\title{
Biometric studies of the eyeball and retinal detachment
}

\author{
GERD MEYER-SCHWICKERATH AND EDMUND GERKE
}

From Essen University Eye Clinic, Essen, West Germany

SUMMARY The relationship between axial length and equatorial diameter and eye volume has been studied in 4 groups of eyes: intact emmetropic eyes, emmetropic eyes with retinal detachment, eyes with moderate myopia and retinal detachment, and eyes with high myopia and retinal detachment. It was found that eyes with detached retinas, regardless of whether they are myopic or emmetropic, are of significantly different dimensions from emmetropic control eyes. There is usually a significant increase in equatorial diameter and therefore in equatorial circumference. The results indicate that eyes with detached retinas differ from normal eyes in their abnormally large size.

The idea for this study of the correlation between eyeball size and retinal detachment dates back to Oswald Marchesani, my (G. M.-S.) first clinical teacher in ophthalmology, who was interested in the relation between the posterior vitreous and retinal detachment. He told me of the tedious and lengthy work involved in optical examination of the posterior vitreous with Lindner's reduction prism or Koepe's silver mirror. In discussing the subject I said that most likely patients with detached retinas had eyes with a large vitreous volume. Unfortunately at that time ultrasonography was not available, and it was impossible to measure the sagittal visual axis or the equatorial diameter of the eye with any degree of accuracy.

Since then echographic studies have shown that eyes with similar refraction may vary considerably in size. ${ }^{1-3}$ It is not known, however, how much these differences in globe size contribute to the pathogenesis of retinal detachment. ${ }^{4}$

\section{Materials and methods}

One hundred myopic and nonmyopic eyes, with and without retinal detachment, were measured with the aid of a Kretztechnik A-scan, model 7200 MA, ultrasound probe NM 8-5K. The eyes examined were divided into the following 4 groups: (1) 25 intact emmetropic eyes (control); (2) 25 emmetropic eyes with rhegmatogenous retinal detachment; (3) 25 eyes with moderate myopia $(-5 \cdot 2 \pm 1 \cdot 8 \mathrm{D})$ and retinal detachment; (4) 25 eyes with high myopia $(-12 \cdot 9 \pm 3 \cdot 4$ D) and retinal detachment.

Correspondence to Professor G. Meyer-Schwickerath.
The 25 emmetropic control eyes $(-1 \cdot 0$ to $+1 \cdot 0 \mathrm{D})$ were analogous to the 25 emmetropic eyes with retinal detachment $(-1.0$ to $+1.0 \mathrm{D})$ as pertains to sex, age ( \pm 4 years), and body size $( \pm 3 \mathrm{~cm})$. The 50 myopic eyes with retinal detachment were not selected according to these criteria.

Ten ultrasonographic measurements were made at inclinations of $48^{\circ}, 69^{\circ}$, and $90^{\circ}$ to the optical axis (Fig. 1).

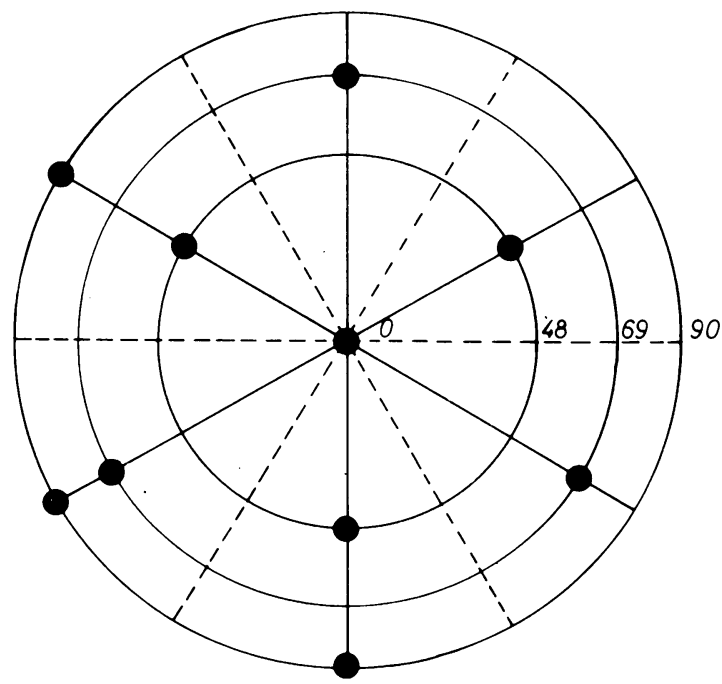

temporal

nasal

Fig. 1 Ultrasonographic measurements of eye parameters at angles of $48^{\circ}, 69^{\circ}$, and $90^{\circ}$ to the optical axis. 

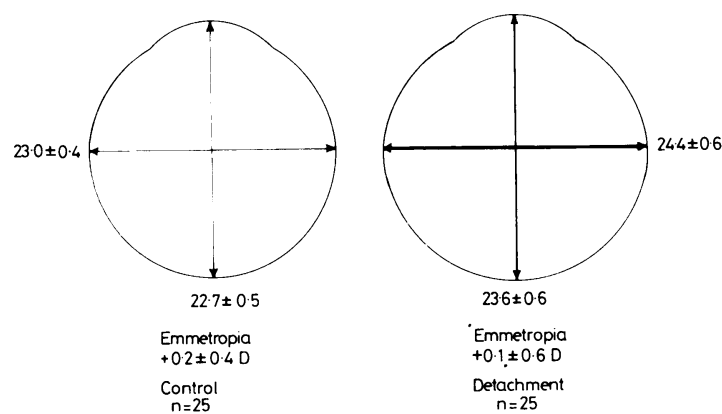

Fig. 2 The sagittal and equatorial diameters of 25 emmetropic eyes with retinal detachment and 25 emmetropic eyes without retinal detachment.
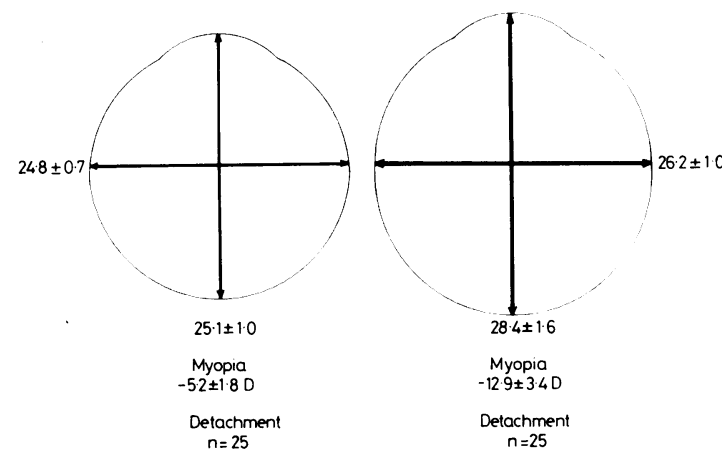

Fig. 3 The sagittal and equatorial diameters of 25 eyes with moderate myopia and retinal detachment and 25 eyes with high myopia and retinal detachment.

\section{Results}

The results of the measurements are shown in Figs. 2 and 3 . The emmetropic eyes with retinal detachment showed a slightly greater axial length than that of the emmetropic control eyes. In both groups emmetropia was possibly due to refraction compensation provided by the cornea and the lens. Especially striking is the fact that the equatorial diameter of the eyes with retinal detachment was $1.4 \mathrm{~mm}$ greater than that of the emmetropic control eyes. By the Wilcoxon test we found that this difference was highly significant $(p<0 \cdot 01)$. Using the equatorial diameter to calculate

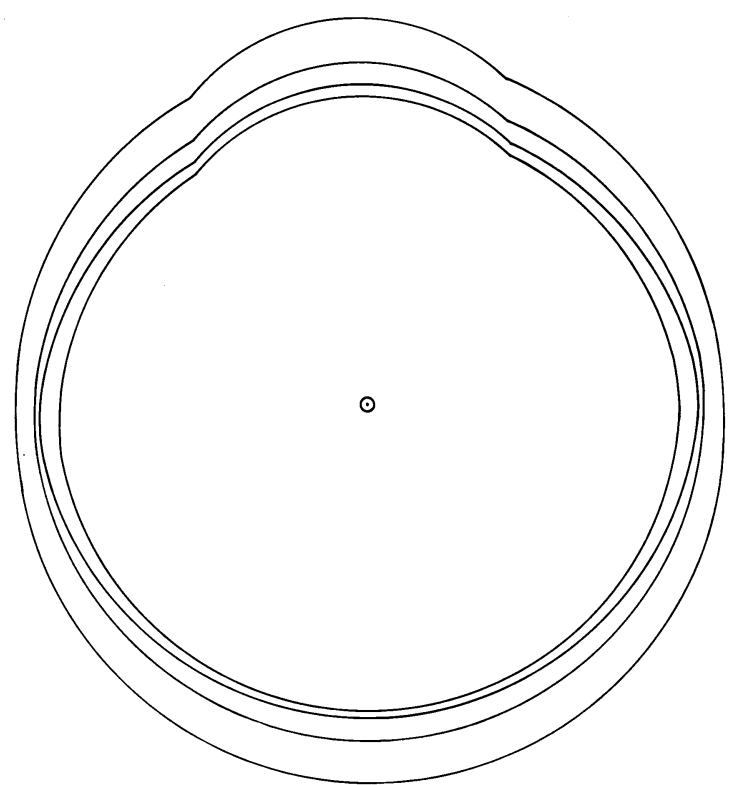

Fig. 4 The average globe size of each of the 4 groups of eyes, drawn from a common midpoint.

the equatorial circumference, we obtained a mean difference of $4.4 \mathrm{~mm}$.

The eyes with moderate myopia $(-5 \cdot 2 \pm 1 \cdot 8 \mathrm{D})$ and retinal detachment showed a significantly greater axial length than that of the control eyes; the equatorial diameter was essentially the same (a difference of $0.4 \mathrm{~mm}$ ).

Again by the Wilcoxon test the eyes with high myopia (-12.9 $\pm 3 \cdot 4 \mathrm{D})$ and retinal detachment were found to have both axial length and equatorial diameter significantly greater than those of the control eyes.

To compare relative eye size the 4 average globe drawings were superimposed, a common mid-point being used for the diameter (Fig. 4). In the diagram the innermost circle represents the group of emmetropic control eyes. It is surrounded by the emmetropic eyes with retinal detachment. It can be seen that the equatorial axis was greater in the second group. The third circle, representing the eyes with

Table 1 The mean sagittal length, equatorial diameter, and globe volume of each of the 4 groups of eyes.

\begin{tabular}{llcc}
\hline & $\begin{array}{l}\text { Sagittal } \\
\text { length } \\
(\mathrm{mm})\end{array}$ & $\begin{array}{l}\text { Equatorial } \\
\text { diameter } \\
(\mathrm{mm})\end{array}$ & $\begin{array}{l}\text { Volume of } \\
\text { the globe } \\
(\mathrm{ml})\end{array}$ \\
\hline Emmetropic control eyes without detachment $+2 \cdot 0 \pm 0 \cdot 4 \mathrm{D}, \mathrm{n}=25$ & $22 \cdot 7 \pm 0 \cdot 5$ & $23 \cdot 0 \pm 0 \cdot 4$ & $6 \cdot 32 \pm 0 \cdot 3$ \\
Emmetropic eyes with detachment $+0 \cdot 1 \pm 0 \cdot 6 \mathrm{D}, \mathrm{n}=25$ & $23 \cdot 6 \pm 0 \cdot 6$ & $24 \cdot 4 \pm 0 \cdot 6$ & $7 \cdot 36 \pm 0 \cdot 5$ \\
Myopic eyes with detachment $-5 \cdot 2 \pm 1 \cdot 8 \mathrm{D}, \mathrm{n}=25$ & $25 \cdot 1 \pm 1 \cdot 0$ & $24 \cdot 8 \pm 0 \cdot 7$ & $8 \cdot 09 \pm 0 \cdot 74$ \\
High myopic eyes with detachment $-12 \cdot 9 \pm 3 \cdot 4 \mathrm{D}, \mathrm{n}=25$ & $28 \cdot 4 \pm 1 \cdot 6$ & $26 \cdot 2 \pm 1 \cdot 0$ & $10 \cdot 28 \pm 1 \cdot 2$ \\
\hline
\end{tabular}


moderate myopia and retinal detachment, showed a symmetrical increase in size throughout the entire globe in comparison with the emmetropic control group. Conversely, the high myopic eyes with retinal detachment showed an asymmetrical increase in both axial length and equatorial diameter.

The axial length and the equatorial diameter were used to calculate the mean globe volume of each of the 4 different groups (Table 1). The following values were obtained: emmetropic control eyes $6 \cdot 32 \pm 0 \cdot 31$ $\mathrm{ml}$, emmetropic eyes with retinal detachment $7 \cdot 36 \pm 0 \cdot 5 \mathrm{ml}$, eyes with moderate myopia and retinal detachment $8 \cdot 09 \pm 0 \cdot 74 \mathrm{ml}$, eyes with high myopia and retinal detachment $10 \cdot 28 \pm 1 \cdot 20 \mathrm{ml}$. There was a highly significant difference $(\mathrm{p}<0.01)$ between the volume of the control eyes and that of the 3 other groups.

\section{Discussion}

In our study we found that eyes with retinal detachment, whether myopic or emmetropic, are of different dimensions from normal control eyes. Owing to a significant increase in sagittal length, equatorial diameter, or in both these parameters the volume of the globe is greatly increased. We believe that this is a very important finding that may be of prognostic value for risk factors in the fellow eye in cases of detached retina and also in cases of patients with vitroretinal degeneration.

\section{References}

1 Dominguez A. Ultrasonic control of ocular dimensions and surgical indentations in retinal detachment. Mod Probl Ophthalmol 1977; 18: 77-81.

2 François J, Goes F. Ultrasonic study of 100 emmetropic eyes. Ophthalmologica 1977; 175: 321-7.

3 Rivara A, Zingirian M. Rilievi biometrici sulla lunghezza dei vari assi oculari e sul volume del bulbo. Ann Ottal 1965; 91: 1233-8.

4 Gerke E. Dimensionen des Bulbus bei ablatio retinae. Ber Dtsch Ophthalmol Ges 1979; 76: 549-52. 